\title{
Kynurenic Acid Content in Selected Culinary Herbs and Spices
}

\author{
Michal P. Turski, ${ }^{1}$ Monika Turska, ${ }^{2}$ Tomasz Kocki, ${ }^{2}$ \\ Waldemar A. Turski, ${ }^{2}$ and Piotr Paluszkiewicz ${ }^{1}$ \\ ${ }^{1}$ Department of Surgery and Surgical Nursing, Medical University, Chodzki 6, 20-090 Lublin, Poland \\ ${ }^{2}$ Department of Experimental and Clinical Pharmacology, Medical University, Ceramiczna 1, 20-150 Lublin, Poland \\ Correspondence should be addressed to Waldemar A. Turski; turskiwa@op.pl
}

Received 26 November 2014; Accepted 6 March 2015

Academic Editor: Pranav S. Shrivastav

Copyright (C) 2015 Michal P. Turski et al. This is an open access article distributed under the Creative Commons Attribution License, which permits unrestricted use, distribution, and reproduction in any medium, provided the original work is properly cited.

\begin{abstract}
Previous studies demonstrated that kynurenic acid (KYNA) is present in various types of food in varying concentrations. Therefore, the aim of the study was to check whether KYNA is present in culinary herbs and spices. Achieved results indicate that KYNA is present in all 19 selected culinary herbs and spices. The highest concentration of KYNA was found in basil and thyme, 14.08 and $8.87 \mu \mathrm{g} / \mathrm{g}$, respectively, while the lowest content of KYNA was found in cumin and black pepper, 0.64 and $0.10 \mu \mathrm{g} / \mathrm{g}$, respectively. This is the first report on the concentration of KYNA in culinary herbs and spices. The need for more detailed investigation of dietary supplementation with culinary herbs and spices containing KYNA is suggested.
\end{abstract}

\section{Introduction}

Kynurenic acid (KYNA) is a natural substance whose presence was first demonstrated in urine by Liebig in 1853 [1]. It did not attract scientists' attention until the 1980s and 1990s when it was found that KYNA is an antagonist of ionotropic glutamate receptors, including N-methylD-aspartate (NMDA), $\alpha$-amino-3-hydroxy-5-methyl-4isoxazolepropionic acid (AMPA), and kainate receptors [2-6]. Afterwards, it was also demonstrated that KYNA is an antagonist of alpha7 nicotinic receptors [7]. Interestingly, both ionotropic glutamate receptors and alpha7 nicotinic receptors are mainly present in the brain. It was also proven that KYNA is present in the brain $[8,9]$ and that it can be synthesized in the brain along the kynurenine pathway [10]. An increased content of KYNA was found in schizophrenia, Alzheimer's disease [11, 12], meningitis, autoimmune diseases, and inflammation [13]. On the other hand, a decreased concentration of KYNA was found in Parkinson's disease [14], Huntington's disease [15], and multiple sclerosis [16]. Due to varying results it is not possible to firmly state the role of KYNA in the central nervous system. Nevertheless, it should be emphasized that the penetration of KYNA through the blood-brain barrier in physiological conditions is limited
[17]. Therefore, a separate analysis of KYNA's presence and actions outside of the brain is necessary. It was found that KYNA is present in human blood and peripheral organs of the body [18-20]. Additionally, it was indicated that KYNA is an agonist of GPR35 receptors which are mainly present in the gastrointestinal tract [21]. Importantly, concentrations of KYNA in the digestive system gradually increase along the gastrointestinal tract. The lowest concentration was found in saliva while the highest in mucus of rat's ileum [22]. The reason for this gradual increase in KYNA content is not known as is the source of KYNA in the gastrointestinal tract. It was proven that KYNA can be synthesized enzymatically in the human body from tryptophan administered orally [23]. Furthermore, it was suggested that KYNA might be absorbed from the digestive system to the blood stream and then transported to other tissues. Intragastric administration of KYNA increased KYNA content in serum, liver, and kidneys in rats [24]. Moreover, drinking water with added KYNA was accepted by animals and did not cause any toxic effects [24]. Achieved results indicate that KYNA might be either synthesized in the human body or absorbed from food and drinks.

The role of KYNA in the periphery is not fully known. It was, however, shown that KYNA possesses numerous 
positive properties, including mainly antiulcerative, antioxidative, and anti-inflammatory properties. It may, therefore, positively influence a number of gastrointestinal tract pathologies, especially ulcers and colitis (see for review [25]). There may be some dispute whether KYNA plays a positive or a negative role in bowel diseases since its concentration in irritable bowel syndrome patients is decreased [26, 27] while in inflammatory bowel disease patients is increased [28]. Nevertheless, it seems as if KYNA possessed mostly positive properties in the gastrointestinal tract which suggests its daily consumption should be analysed and controlled.

Earlier studies showed that KYNA is a constituent of various types of food and that its concentration in food varies. The highest concentration of KYNA was found in vegetables and honey while the lowest was found in meat [29]. Furthermore, it was shown that the content of KYNA is different in various parts of a plant-the highest content was found in leaves while the lowest was found in rootsand it was shown that a plant might either synthesize KYNA from its precursor, kynurenine, or absorb it from the ground [29]. KYNA was also found in various herbs and herbal preparations; the highest concentrations of KYNA were found in St. John's wort, nettle leaf, birch leaf, elderberry flower, and peppermint leaf, all of which are believed to possess healing and protective properties when it comes to the digestive system. Therefore, the goal of this study was to investigate whether selected culinary herbs and spices that are of a plant origin contain KYNA.

\section{Materials and Methods}

2.1. Standard and Reagents. Kynurenic acid (KYNA) was purchased from Sigma (St. Louis, MO, USA). All high performance liquid chromatography (HPLC) reagents were purchased from J.T. Baker (Deventer, Netherlands) or Sigma (St. Louis, MO, USA) and were of the highest available purity. For extraction of KYNA, cation exchange resin Dowex 50 WX4-400 purchased from Sigma (St. Louis, MO, USA) was used.

2.2. Materials. All culinary herbs and spices were bought in regular stores. The following items were used: fennel (Foeniculi fructus), mint (Menthae piperitae folium), rosemary (Rosmarini folium), sage (Salvia officinalis) (all distributed by Kawon, Gostyn, Poland); basil, black pepper, cloves, thyme (all distributed by Drogheria \& Alimentari S.p.a., Firenze, Italy); bay leaf, curry powder, Glechoma, herbes de Provence, marjoram, oregano, parsley, savory, tarragon, turmeric (all distributed by Dary Natury, Grodzisk, Poland); and cumin (distributed by Dr Kaldysz, Poznan, Poland).

2.3. Methods. Experiments were performed according to the method described in detail previously [29]. In brief, samples of culinary herbs and spices were weighed and distilled water was added to them $(1: 10 \mathrm{w} / \mathrm{v})$. They were then homogenized and centrifuged $(5,000 \mathrm{rpm}, 10 \mathrm{~min})$ and $1 \mathrm{~mL}$ of supernatant was collected. Samples were then acidified with $50 \%$ trichloroacetic acid and vortexed. Denatured proteins were
TABLE 1: KYNA content in analysed spices and herbs.

\begin{tabular}{lccc}
\hline Spice & KYNA $[\mu \mathrm{g} / \mathrm{g}]$ & SD & Plant part \\
\hline Basil & 14.08 & 1.33 & Leaves \\
Thyme & 8.87 & 0.83 & Leaves and branches \\
Marjoram & 3.78 & 0.08 & Herbs \\
Curry powder & 3.39 & 0.26 & Mixture of herbs \\
Herbes de Provence & 3.20 & 0.07 & Mixture of herbs \\
Mint & 3.02 & 0.32 & Leaves \\
Oregano & 2.50 & 0.22 & Leaves \\
Savory & 2.37 & 0.07 & Herbs \\
Turmeric & 1.48 & 0.03 & Rhizoma \\
Sage & 1.28 & 0.14 & Leaves \\
Rosemary & 1.21 & 0.04 & Leaves \\
Cloves & 1.29 & 0.07 & Flower buds \\
Tarragon & 1.04 & 0.04 & Leaves \\
Glechoma & 1.01 & 0.03 & Herbs \\
Bay leaf & 0.91 & 0.01 & Leaves \\
Fennel & 0.80 & 0.10 & Fruits \\
Parsley & 0.76 & 0.09 & Leaves \\
Cumin & 0.64 & 0.03 & Seeds \\
Black pepper & 0.10 & 0.01 & Fruits \\
\hline
\end{tabular}

KYNA: kynurenic acid; SD: standard deviation.

removed by centrifugation $(12,000 \mathrm{rpm}, 10 \mathrm{~min})$. Samples acidified with $1 \mathrm{~N} \mathrm{HCl}$ were applied to the columns containing cation exchange resin Dowex 50 prewashed with $0.1 \mathrm{~N} \mathrm{HCl}$. Subsequently, the columns were washed with $1 \mathrm{~mL}$ of $0.1 \mathrm{~N}$ $\mathrm{HCl}$ and $1 \mathrm{~mL}$ of water. The fraction containing KYNA was eluted with $4 \mathrm{~mL}$ of water. The eluate was subjected to HPLC (Dionex HPLC system; ESA catecholamine HR-80, $3 \mu \mathrm{m}, \mathrm{C} 18$ reverse-phase column) and KYNA was quantified fluorometrically (Dionex RF2000 fluorescence detector; excitation $350 \mathrm{~nm}$, emission $404 \mathrm{~nm}$ ). The mobile phase consisted of $50 \mathrm{mM}$ sodium acetate and $250 \mathrm{mM}$ zinc acetate ( $\mathrm{pH}$ 6.2), containing $5 \%$ of acetonitrile. The flow rate was $1.0 \mathrm{~mL} / \mathrm{min}$.

Original KYNA was added to some of the samples as an internal standard.

2.4. Statistical Analysis. Samples were analysed in triplicate. Data were presented as a mean value and a standard deviation (SD).

\section{Results}

HPLC profile of a substance isolated from culinary herbs and spices was compared with authentic KYNA. In all cases, the shape and the retention time of the peak of isolated substance and authentic KYNA were identical (Figure 1).

KYNA was found in all analysed spices and herbs (Table 1). The highest content of KYNA was found in basil $(14.08 \pm 1.33 \mu \mathrm{g} / \mathrm{g})$ and thyme $(8.87 \pm 0.83 \mu \mathrm{g} / \mathrm{g})$. Concentrations varying from $2.37 \pm 0.07 \mu \mathrm{g} / \mathrm{g}$ through $2.50 \pm 0.22 \mu \mathrm{g} / \mathrm{g}$, $3.02 \pm 0.32 \mu \mathrm{g} / \mathrm{g}, 3.20 \pm 0.07 \mu \mathrm{g} / \mathrm{g}$, and $3.39 \pm 0.26 \mu \mathrm{g} / \mathrm{g}$ up to $3.78 \pm 0.08 \mu \mathrm{g} / \mathrm{g}$ were found in savory, oregano, mint, herbes de Provence, curry powder, and marjoram, 


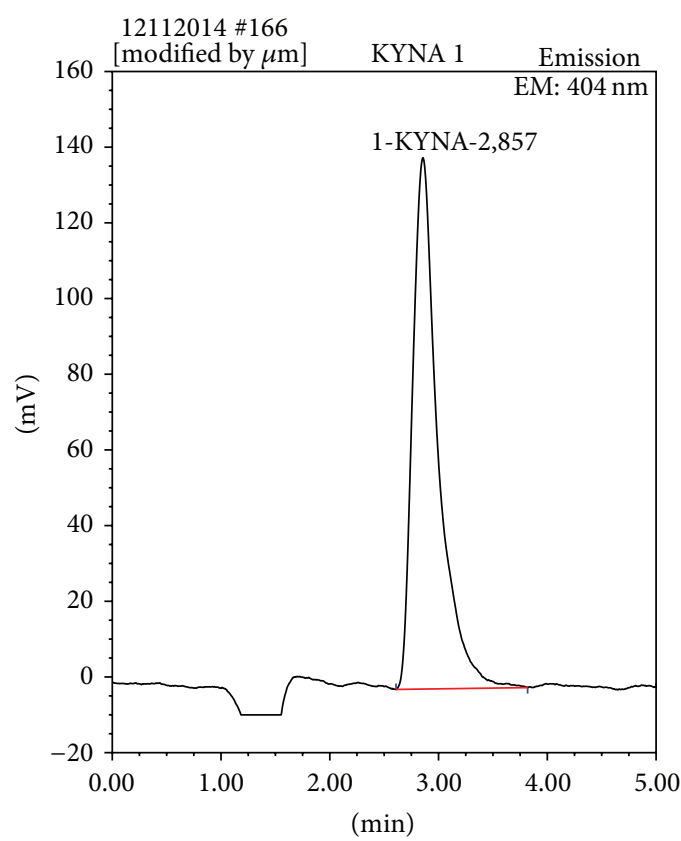

(a)

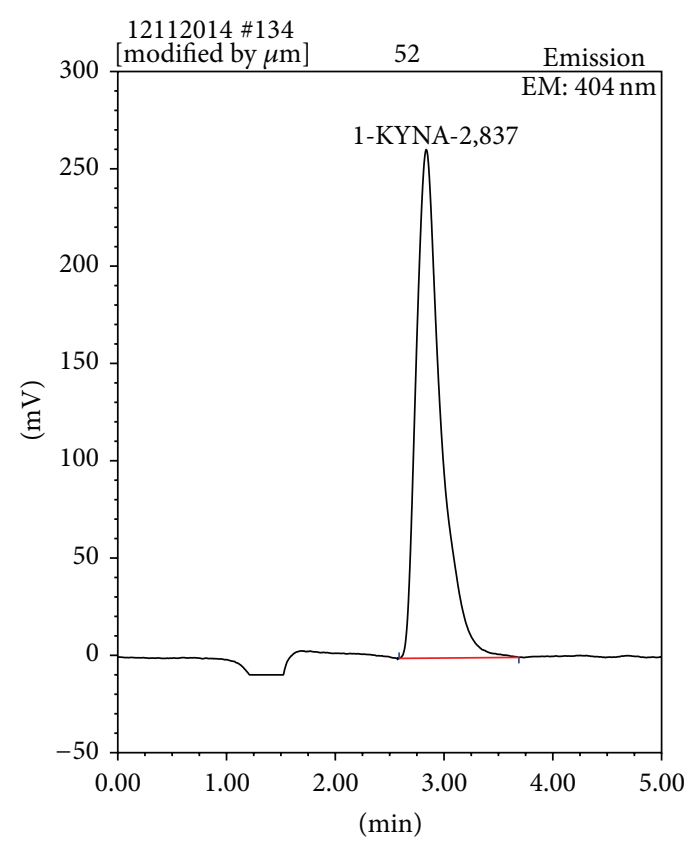

(b)

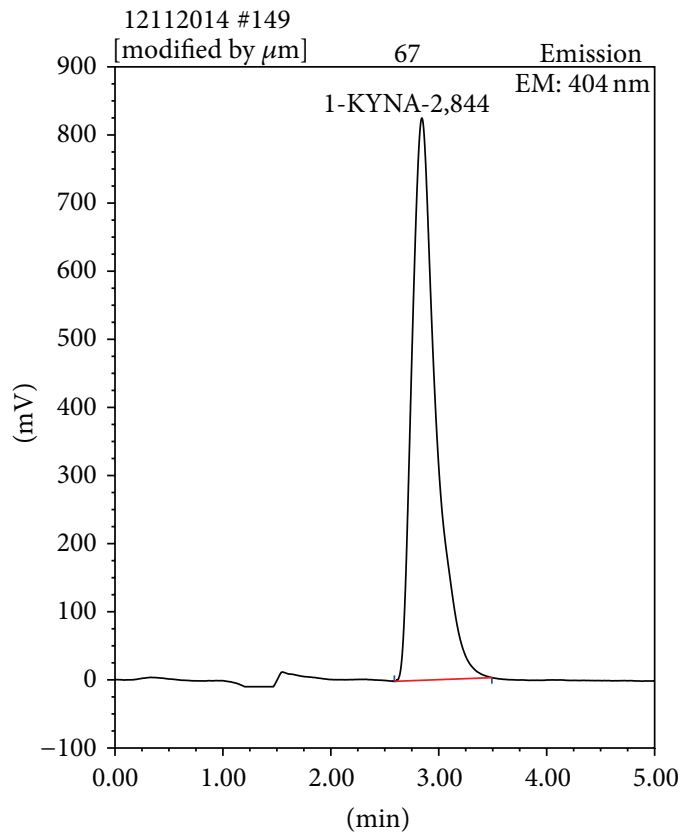

(c)

FIGURE 1: Overlay of samples from integration view. HPLC identification and quantification of KYNA in culinary herbs and spices: (a) authentic KYNA 1 pmol; (b) HPLC profile of a substance extracted from basil; and (c) HPLC profile of a substance extracted from thyme. Note identical retention time and shape of the peak.

respectively. Lower contents of KYNA were discovered in cumin $(0.64 \pm 0.03 \mu \mathrm{g} / \mathrm{g})$, parsley $(0.76 \pm 0.09 \mu \mathrm{g} / \mathrm{g})$, fennel $(0.80 \pm 0.10 \mu \mathrm{g} / \mathrm{g})$, bay leaf $(0.91 \pm 0.01 \mu \mathrm{g} / \mathrm{g})$, Glechoma $(1.01 \pm 0.03 \mu \mathrm{g} / \mathrm{g})$, tarragon $(1.04 \pm 0.04 \mu \mathrm{g} / \mathrm{g})$, cloves $(1.29 \pm$ $0.07 \mu \mathrm{g} / \mathrm{g})$, rosemary $(1.21 \pm 0.04 \mu \mathrm{g} / \mathrm{g})$, sage $(1.28 \pm 0.14 \mu \mathrm{g} / \mathrm{g})$, and turmeric $(1.48 \pm 0.03 \mu \mathrm{g} / \mathrm{g})$. The lowest concentration of KYNA was found in black pepper $(0.10 \pm 0.01 \mu \mathrm{g} / \mathrm{g})$ (Table 1$)$.

\section{Discussion}

KYNA was found in all analysed samples of culinary herbs and spices. Interestingly, the content of KYNA varied significantly between analysed herbs and spices; the content of KYNA in basil was about 140 times higher than the content of KYNA found in black pepper. Based on the fact that 
plants were found to contain, produce, and absorb KYNA from the ground [29] and that all analysed herbs and spices were of a plant origin, achieved results showing that all herbs and spices contain KYNA are not unexpected. Such conclusion is strengthened by the fact that KYNA content in leaves was found to be higher than its content in flowers and roots [29] while the majority of analysed herbs and spices originated from plants' leaves. Interestingly, though, the content of KYNA in herbs and spices was higher than the content of KYNA in all previously analysed foods, including broccoli, potatoes, and honey, which were thought to contain significant amounts of KYNA [30]. Still, when considering a daily intake of KYNA, the amount provided through consumption of herbs and spices will most probably be lower in comparison to the amount provided by the most popular vegetables that contain significant amounts of KYNA, such as broccoli or potatoes. Nevertheless, various herbs and spices may be considered a valuable source of KYNA in an everyday diet since they are used with both vegetables and meats. The fact that they are commonly used along with meats might be meaningful bearing in mind the fact that meats are not a rich source of KYNA [30]. Furthermore, it was shown that diets that contain high amount of meat, especially red meat, are unhealthy and cause numerous pathologies. One of the key findings indicates that high red meat consumption is so strongly correlated with diabetes that it should be treated as one of its risk factors [31]. Furthermore, there are numerous studies showing that an increased consumption of red meat may lead to metabolic diseases, cardiovascular diseases, and obesity $[32,33]$. Researchers also suggest that red meat consumption is directly correlated to some cancers occurring in the gastrointestinal tract. Meta-analyses indicate that the consumption of more than $50 \mathrm{~g}$ of red meat per day may lead to an increased risk of colorectal cancer; still, the crucial risk factor is the regularity of red meat consumption. Moreover, it was shown that red meat consumption may lead to a $27 \%$ increase in the risk of developing pancreatic cancer [34]. These results were confirmed by a research, which showed that the consumption of processed meat and red meat increased the risk of developing pancreatic cancer by $68 \%$ and $50 \%$, respectively. All in all, it may be concluded that diets rich in red meat lead to severe pathologies of not only gastrointestinal tract but the whole organism. Therefore, it seems vital to look for substances, which may protect or limit negative effects exerted by such diets.

Despite the fact that the role of KYNA in the periphery is not yet fully known, numerous positive properties of KYNA were described in the literature. It was indicated that KYNA protects against duodenal and gastric ulceration caused by poisonous Atlantic shellfish [35] and reduces stress- and ethanol-induced ulceration in rats [36]. Furthermore, it was shown that KYNA lowers hypermotility in the intestine and activity of xanthine oxidase in colon obstruction in dogs [37]. KYNA was also found to possess anti-inflammatory properties [38]. Moreover, it was shown that KYNA has antiproliferative properties in colon cancer in vitro [39]. KYNA content was found to be lower in irritable bowel syndrome patients $[26,27]$ while it was found to be higher in inflammatory bowel disease patients [28]. Finally, an increased concentration of KYNA was found in mucus obtained from coecum or ascending colon in patients who suffered from colorectal cancer adenomas [40].

All in all, it seems that KYNA possesses mostly positive properties when it comes to the gastrointestinal tract. Its role in patients suffering from various bowel syndromes needs to be further investigated before any conclusions are derived. When it comes to an increased KYNA content in mucus from coecum or ascending colon in colorectal cancer adenomas patients, there is still no satisfactory explanation. On the one hand, KYNA was found to have antiproliferative properties. On the other hand, it was shown that cancer cells in the intestine produce KYNA more effectively when compared to normal intestine cells. Therefore, further investigation is necessary. As for now, an increased level of KYNA in such patients may be used as a novel marker in gastroenterology [40].

Bearing in mind all the facts pointed out above, culinary herbs and spices, which contain KYNA as was proven in the paper, may become an important dietary supplement. Culinary herbs and spices might be selected based on their content of KYNA, leading to an increase or a decrease in the amount of KYNA in a diet depending on the specific needs of a person. Such dietary supplementation using specific culinary herbs and spices needs further investigation.

\section{Disclosure}

Michal P. Turski is a doctoral student and volunteer at the Department of Surgery and Surgical Nursing, Medical University in Lublin. Monika Turska is a student and volunteer at the Department of Experimental and Clinical Pharmacology, Medical University in Lublin.

\section{Conflict of Interests}

The authors declare that there is no conflict of interests regarding the publication of this paper.

\section{References}

[1] J. Liebig, “Über Kynurensäure," Justus Liebigs Annalen der Chemie, vol. 86, pp. 125-126, 1853.

[2] A. Alt, B. Weiss, A. M. Ogden et al., "Pharmacological characterization of glutamatergic agonists and antagonists at recombinant human homomeric and heteromeric kainate receptors in vitro," Neuropharmacology, vol. 46, no. 6, pp. 793-806, 2004.

[3] A. H. Ganong and C. W. Cotman, "Kynurenic acid and quinolinic acid act at N-methyl-D-aspartate receptors in the rat hippocampus," Journal of Pharmacology and Experimental Therapeutics, vol. 236, no. 1, pp. 293-299, 1986.

[4] J. A. Kemp, A. C. Foster, P. D. Leeson et al., "7-Chlorokynurenic acid is a selective antagonist at the glycine modulatory site of the N-methyl-D-aspartate receptor complex," Proceedings of the National Academy of Sciences of the United States of America, vol. 85, no. 17, pp. 6547-6550, 1988.

[5] M. Kessler, T. Terramani, G. Lynch, and M. Baudry, "A glycine site associated with $\mathrm{N}$-methyl-D-aspartic acid receptors: characterization and identification of a new class of antagonists," Journal of Neurochemistry, vol. 52, no. 4, pp. 1319-1328, 1989. 
[6] M. H. S. Mok, A.-C. Fricker, A. Weil, and J. N. C. Kew, "Electrophysiological characterisation of the actions of kynurenic acid at ligand-gated ion channels," Neuropharmacology, vol. 57, no. 3, pp. 242-249, 2009.

[7] C. Hilmas, E. F. R. Pereira, M. Alkondon, A. Rassoulpour, R. Schwarcz, and E. X. Albuquerque, "The brain metabolite kynurenic acid inhibits $\alpha 7$ nicotinic receptor activity and increases non- $\alpha 7$ nicotinic receptor expression: physiopathological implications," Journal of Neuroscience, vol. 21, no. 19, pp. 7463-7473, 2001.

[8] F. Moroni, P. Russi, G. Lombardi, M. Beni, and V. Carla, "Presence of kynurenic acid in the mammalian brain," Journal of Neurochemistry, vol. 51, no. 1, pp. 177-180, 1988.

[9] W. A. Turski, M. Nakamura, W. P. Todd, B. K. Carpenter, W. O. Whetsell Jr., and R. Schwarcz, "Identification and quantification of kynurenic acid in human brain tissue," Brain Research, vol. 454, no. 1-2, pp. 164-169, 1988.

[10] F. Du, W. Schmidt, E. Okuno, R. Kido, C. Kohler, and R. Schwarcz, "Localization of kynurenine aminotransferase immunoreactivity in the rat hippocampus," Journal of Comparative Neurology, vol. 321, no. 3, pp. 477-487, 1992.

[11] S. Erhardt, K. Blennow, C. Nordin, E. Skogh, L. H. Lindström, and G. Engberg, "Kynurenic acid levels are elevated in the cerebrospinal fluid of patients with schizophrenia," Neuroscience Letters, vol. 313, no. 1-2, pp. 96-98, 2001.

[12] R. Schwarcz, A. Rassoulpour, H.-Q. Wu, D. Medoff, C. A. Tamminga, and R. C. Roberts, "Increased cortical kynurenate content in schizophrenia," Biological Psychiatry, vol. 50, no. 7, pp. 521-530, 2001.

[13] M. P. Heyes, K. Saito, J. S. Crowley et al., "Quinolinic acid and kynurenine pathway metabolism in inflammatory and noninflammatory neurological disease," Brain, vol. 115, no. 5, pp. 1249-1273, 1992.

[14] T. Ogawa, W. R. Matson, M. F. Beal et al., "Kynurenine pathway abnormalities in Parkinson's disease," Neurology, vol. 42, no. 9, pp. 1702-1706, 1992.

[15] D. Jauch, E. M. Urbańska, P. Guidetti et al., "Dysfunction of brain kynurenic acid metabolism in Huntington's disease: focus on kynurenine aminotransferases," Journal of the Neurological Sciences, vol. 130, no. 1, pp. 39-47, 1995.

[16] K. Rejdak, H. Bartosik-Psujek, B. Dobosz et al., "Decreased level of kynurenic acid in cerebrospinal fluid of relapsing-onset multiple sclerosis patients," Neuroscience Letters, vol. 331, no. 1, pp. 63-65, 2002.

[17] S. Fukui, R. Schwarcz, S. I. Rapoport, Y. Takada, and Q. R. Smith, "Blood-brain barrier transport of kynurenines: implications for brain synthesis and metabolism," Journal of Neurochemistry, vol. 56, no. 6, pp. 2007-2017, 1991.

[18] A. Amirkhani, E. Heldin, K. E. Markides, and J. Bergquist, "Quantitation of tryptophan, kynurenine and kynurenic acid in human plasma by capillary liquid chromatography-electrospray ionization tandem mass spectrometry," Journal of Chromatography B, vol. 780, no. 2, pp. 381-387, 2002.

[19] Z. Hartai, P. Klivenyi, T. Janaky, B. Penke, L. Dux, and L. Vecsei, "Kynurenine metabolism in multiple sclerosis," Acta Neurologica Scandinavica, vol. 112, no. 2, pp. 93-96, 2005.

[20] B. Kepplinger, H. Baran, A. Kainz, H. Ferraz-Leite, J. Newcombe, and P. Kalina, "Age-related increase of kynurenic acid in human cerebrospinal fluid-IgG and $\beta_{2}$-microglobulin changes," NeuroSignals, vol. 14, no. 3, pp. 126-135, 2005.

[21] J. Wang, N. Simonavicius, X. Wu et al., "Kynurenic acid as a ligand for orphan G protein-coupled receptor GPR35," The
Journal of Biological Chemistry, vol. 281, no. 31, pp. 22021-22028, 2006.

[22] D. Kuc, W. Zgrajka, J. Parada-Turska, T. Urbanik-Sypniewska, and W. A. Turski, "Micromolar concentration of kynurenic acid in rat small intestine," Amino Acids, vol. 35, no. 2, pp. 503-505, 2008.

[23] C. Hiratsuka, T. Fukuwatari, and K. Shibata, "Fate of dietary tryptophan in young Japanese women," International Journal of Tryptophan Research, vol. 5, no. 1, pp. 33-47, 2012.

[24] W. A. Turski, J. Małaczewska, S. Marciniak et al., "On the toxicity of kynurenic acid in vivo and in vitro," Pharmacological Reports, vol. 66, no. 6, pp. 1127-1133, 2014.

[25] M. P. Turski, M. Turska, P. Paluszkiewicz, J. Parada-Turska, and G. F. Oxenkrug, "Kynurenic Acid in the digestive systemnew facts, new challenges," International Journal of Tryptophan Research, vol. 6, pp. 47-55, 2013.

[26] G. Clarke, P. Fitzgerald, J. F. Cryan, E. M. Cassidy, E. M. Quigley, and T. G. Dinan, "Tryptophan degradation in irritable bowel syndrome: evidence of indoleamine 2,3-dioxygenase activation in a male cohort," BMC Gastroenterology, vol. 9, no. 1, article 6, 2009.

[27] D. M. Christmas, A. A.-B. Badawy, D. Hince et al., "Increased serum free tryptophan in patients with diarrhea-predominant irritable bowel syndrome," Nutrition Research, vol. 30, no. 10, pp. 678-688, 2010.

[28] C. M. Forrest, S. R. Gould, L. G. Darlington, and T. W. Stone, "Levels of purine, kynurenine and lipid peroxidation products in patients with inflammatory bowel disease," Advances in Experimental Medicine and Biology, vol. 527, pp. 395-400, 2003.

[29] M. P. Turski, M. Turska, W. Zgrajka, M. Bartnik, T. Kocki, and W. A. Turski, "Distribution, synthesis, and absorption of kynurenic acid in plants," Planta Medica, vol. 77, no. 8, pp. 858864, 2011.

[30] M. P. Turski, M. Turska, W. Zgrajka, D. Kuc, and W. A. Turski, "Presence of kynurenic acid in food and honeybee products," Amino Acids, vol. 36, no. 1, pp. 75-80, 2009.

[31] N. Barnard, S. Levin, and C. Trapp, "Meat consumption as a risk factor for type 2 diabetes," Nutrients, vol. 6, no. 2, pp. 897-910, 2014.

[32] N. Babio, M. Sorlí, M. Bulló et al., "Association between red meat consumption and metabolic syndrome in a Mediterranean population at high cardiovascular risk: cross-sectional and 1year follow-up assessment," Nutrition, Metabolism and Cardiovascular Diseases, vol. 22, no. 3, pp. 200-207, 2012.

[33] P. G. Cocate, A. J. Natali, A. D. Oliveira et al., "Red but not white meat consumption is associated with metabolic syndrome, insulin resistance and lipid peroxidation in Brazilian middleaged men," European Journal of Preventive Cardiology, vol. 22, no. 2, pp. 223-230, 2015.

[34] P. Paluszkiewicz, K. Smolińska, I. Debińska, and W. A. Turski, "Main dietary compounds and pancreatic cancer risk. The quantitative analysis of case-control and cohort studies," Cancer Epidemiology, vol. 36, no. 1, pp. 60-67, 2012.

[35] G. B. Glavin, R. Bose, and C. Pinsky, "Kynurenic acid protects against gastroduodenal ulceration in mice injected with extracts from poisonous Atlantic shellfish," Progress in NeuroPsychopharmacology \& Biological Psychiatry, vol. 13, no. 3-4, pp. 569-572, 1989.

[36] G. B. Glavin and C. Pinsky, "Kynurenic acid attenuates experimental ulcer formation and basal gastric acid secretion in rats," Research Communications in Chemical Pathology and Pharmacology, vol. 64, no. 1, pp. 111-119, 1989. 
[37] J. Kaszaki, Z. Palásthy, D. Érczes et al., "Kynurenic acid inhibits intestinal hypermotility and xanthine oxidase activity during experimental colon obstruction in dogs," Neurogastroenterology and Motility, vol. 20, no. 1, pp. 53-62, 2008.

[38] G. Varga, D. Érces, B. Fazekas et al., "N-Methyl-d-aspartate receptor antagonism decreases motility and inflammatory activation in the early phase of acute experimental colitis in the rat," Neurogastroenterology \& Motility, vol. 22, no. 2, pp. 217-225, 2010.

[39] K. Walczak, W. A. Turski, and G. Rajtar, "Kynurenic acid inhibits colon cancer proliferation in vitro: effects on signaling pathways," Amino Acids, vol. 46, no. 10, pp. 2393-2401, 2014.

[40] K. Walczak, W. Dab̧rowski, E. Langner et al., "Kynurenic acid synthesis and kynurenine aminotransferases expression in colon derived normal and cancer cells," Scandinavian Journal of Gastroenterology, vol. 46, no. 7-8, pp. 903-912, 2011. 

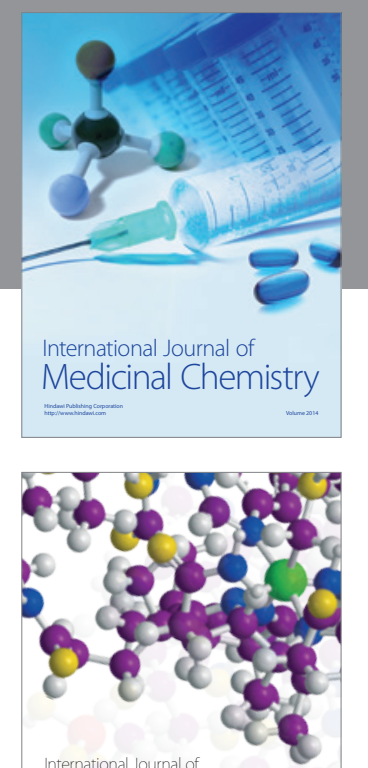

\section{Carbohydrate} Chemistry

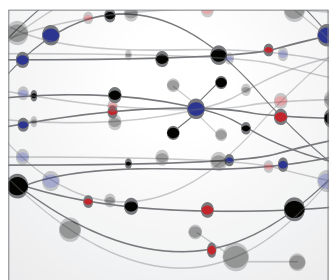

The Scientific World Journal
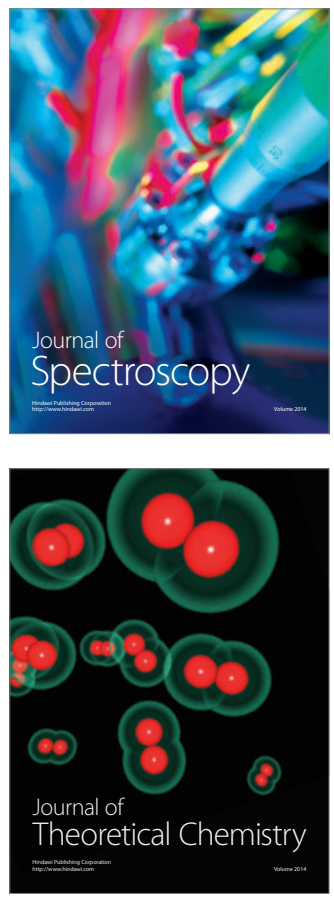
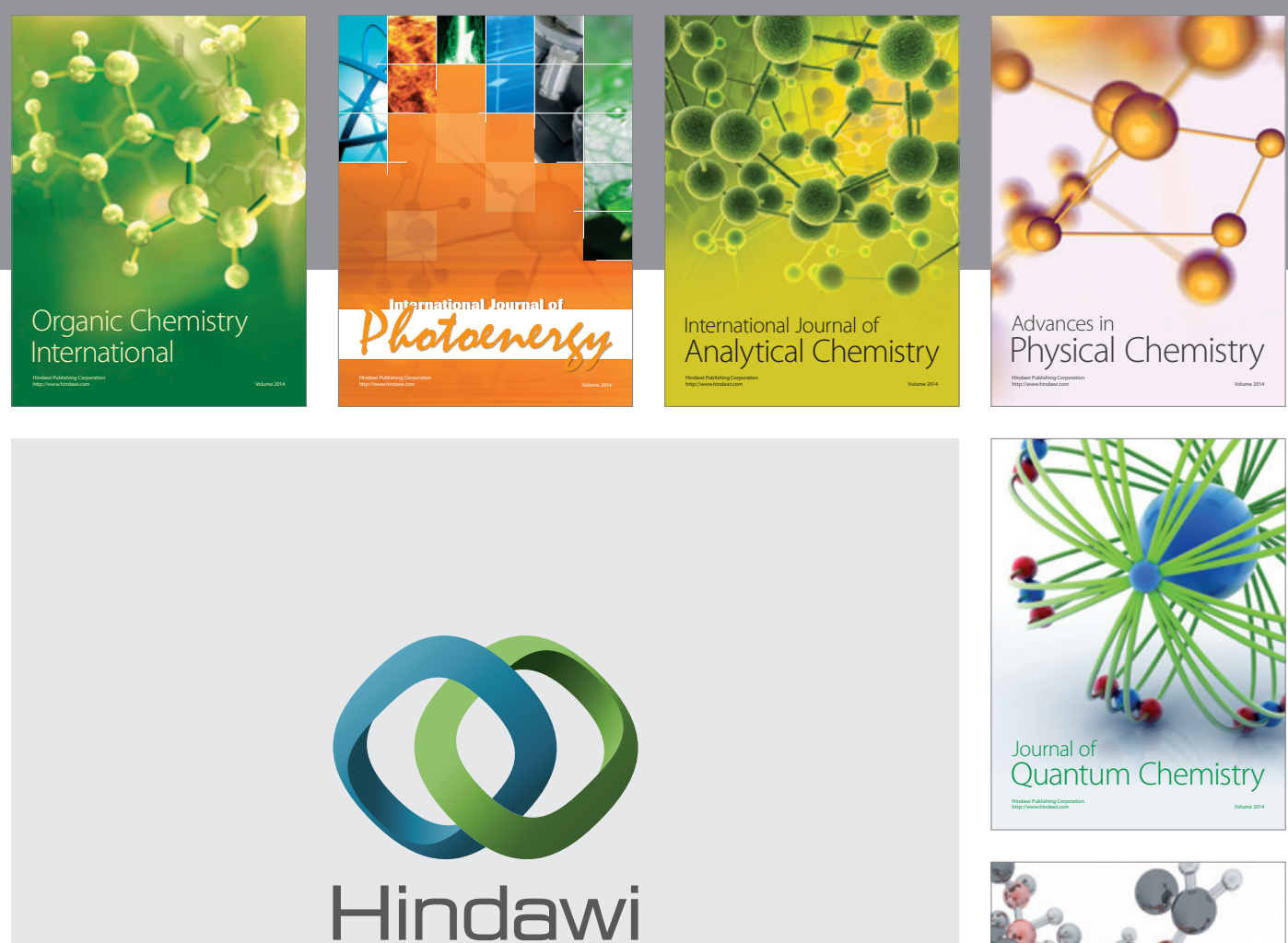

Submit your manuscripts at

http://www.hindawi.com

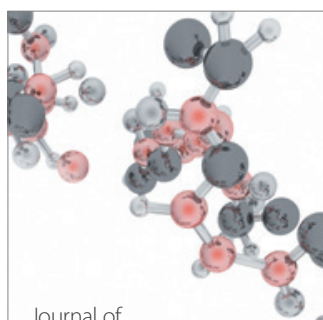

Analytical Methods

in Chemistry

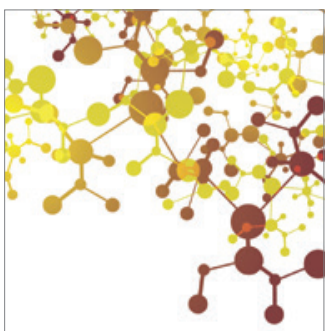

Journal of

Applied Chemistry

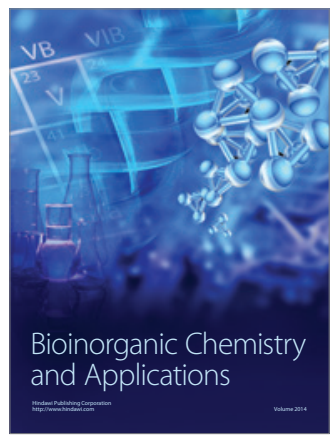

Inorganic Chemistry
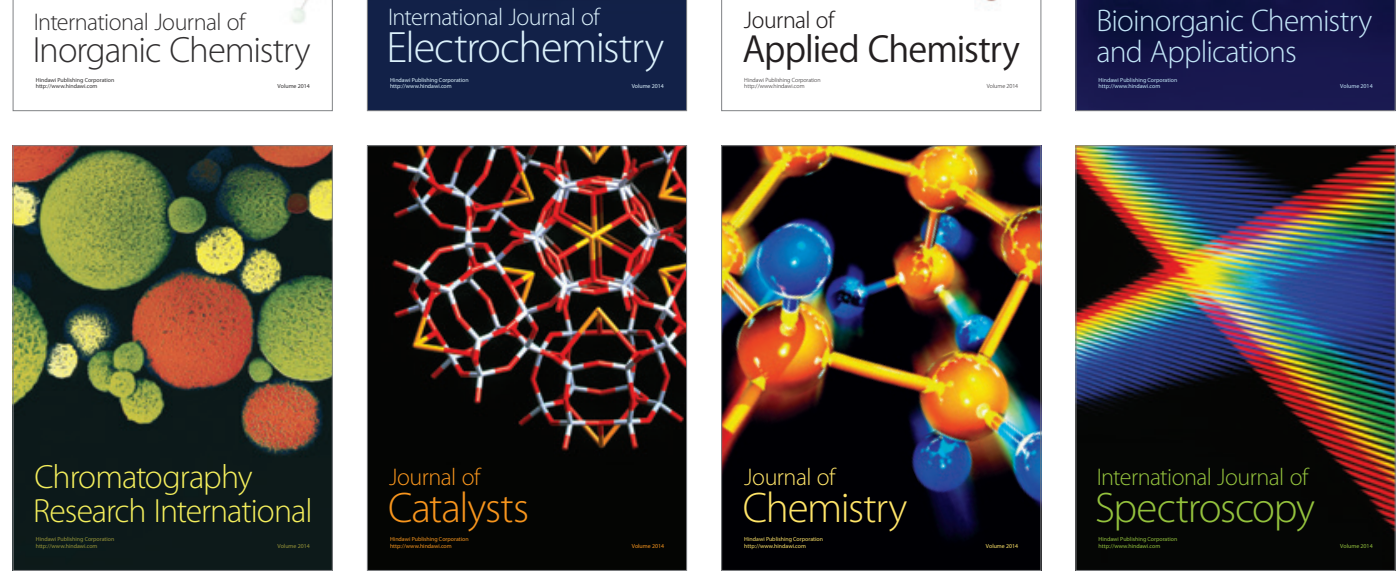